\title{
Study on Prevalence and Predictors of Polypharmacy in Geriatric Patients at a Private Corporate Hospital
}

\author{
Sriram $S^{1}$, Jambulingam $P^{2}$, Muthuswamy $K^{3}$, Aarya $S^{4}$, Sofy Binu ${ }^{5}$, Sweatha Annie Mooken ${ }^{6}$ \\ ${ }^{1,3,4,5,6}$ College of Pharmacy, Sri Ramakrishna Institute of Para Medical Sciences, Coimbatore \\ ${ }^{2}$ Consultant Physician, Dept of General Medicine, Sri Ramakrishna Hospital, Coimbatore
}

\begin{abstract}
A prospective study on predictors of polypharmacy in Geriatrics was conducted in the General Medicine department of a 750 bedded multi-specialty private hospital in South India. A total of 124 geriatric patients were enrolled in the study of which $59 \%$ were male patients and $41 \%$ were female patients. The analysis of results of the study conducted revealed that $54.73 \%$ of population were prescribed with 6-10 drugs, 37.09\% with 11-15 drugs and 5.64\% with 16-20 drugs. Our study assessed Potentially Inappropriate Medications (PIM) as per Beers Criteria. The results revealed that the PIM use was observed in 48.3\% patients. The analysis also revealed that the association between the number of drugs and number of PIM was statistically significant. Similarly the association between the number of co-morbidities and number of drugs was statistically significant.
\end{abstract}

Keywords: Polypharmacy, Geriatric patients, Beer's criteria, PIM

\section{Introduction}

The term polypharmacy refers to the group of medications one person may be taking. It comes from two Greek root words: poly, meaning many, and pharmakeia meaning medicines or drugs. It is generally used when that one person is taking too many medications, or when the drugs have been prescribed by many doctors, and may not have been coordinated well. The definition of polypharmacy is still controversial ${ }^{[1]}$. One simple definition is based on the total number of different medications a patient takes concurrently. Topical and herbal medications are generally excluded of this definition as they are often not included in the traditional methods of assessing prescription quality.

Polypharmacy is associated with suboptimal and inappropriate prescribing. Many medications that have an increased tendency to cause problems for older patients have been labeled as inappropriate drugs for this segment of the population. The simplest definition of an inappropriate drug is one that has greater potential to harm than to benefit the patient. It is difficult to state that any given drug should not be used in an elderly patient under any circumstances. Highrisk medications do not cause problems in all elderly patients, but they do have an increased potential to cause problems.

Potentially inappropriate use of medications (PIM) use in the elderly places a significant burden on the healthcare system. PIM is defined as use of a drug with risk of an adverse event that outweighs its clinical benefit, particularly when there is a safer or more effective alternative therapy for the same condition. Beers criteria to assess and reduce the risk of PIM in the elderly by identifying PIM have been developed. The criteria was subsequently updated. Utilization of this criteria has shown PIMs to be associated with a $25 \%$ increase in the risk of hospitalizations in elderly nursing home residents. Sometimes it is accompanied with lots of hazards due to suboptimal prescribing habits as well as medication management ${ }^{[2]}$.

Polypharmacy is not sovereign clinical marker to indicate worthy usage of medicines. Clinical outcomes are indicated by the proper diagnosis, dose \& type of medication not by number of medicines. Higher the number of medicines, more difficult it would be to find proper medication history, also greater chances of ADR development ${ }^{[3]}$

\section{Literature Survey}

An extensive literature survey was carried out regarding the different aspects that should be considered while doing a study based on Polypharmacy. These include the various reasons for Polypharmacy, complications \& risk factors associated with different classes of drug used, management and clinical significance, self care assessment, etc. The literatures supporting the study were gathered from various journals like American Journal of Health-System Pharmacy, British Medical Journal, Universal Journal of Pharmacy, International Journal of Pharmacy and Pharmaceutical Sciences. The journal search and collection of literatures were done utilizing the facilities of IOWA Drug Information System (IDIS), Micromedex, and Medline and from the Internet

\section{Method}

The department selected for the study was the Department of General Medicine.The reason for selection of this department was that, pilot study revealed more prevalence of Geriatric cases in the department of General Medicine. It was also identified that, the Department of General medicine has got lot of potential to use many classes of drugs. Pharmacy practice department provides services to General Medicine Department and a good co-operation from medical team added up to the reason for selecting the department for conducting the study. All the geriatric patients admitted in 


\section{International Journal of Science and Research (IJSR) \\ ISSN (Online): 2319-7064}

Index Copernicus Value (2013): 6.14 | Impact Factor (2014): 5.611

the Department of General Medicine were included in the study. The outpatients and intensive care patients were excluded in the study. A Data Entry Format for collecting patient details was prepared and during the ward rounds the entire patient data were recorded. The collected data were analysed using Beer's criteria for potentially inappropriate medication use in older adults. Beer's list is the list of medication with their guideline to use by health care professionals to improve the prescribing practice for older adults and to ensure safe medication use in elderly. The details regarding the results obtained from the study were evaluated and made as a report and guideline was prepared for appropriate use of drugs in geriatrics.

\section{Results \& Discussion}

The work entitled "Study on prevalence and predictors of polypharmacy in Geriatric Patients at a private corporate hospital" was conducted in the department of general medicine at a 750 bedded multispecialty hospital. During the study 124 patients were enrolled. Prior consent was taken from the patients after explaining them the need of the study.

The analysis of the results of the study revealed that there were $73(59 \%)$ male patients and $51(41 \%)$ female patients who fit into the inclusion criteria (fig.1). Male population were affected more with polypharmacy which is in accordance with the literatures which documented that males are more prone to polypharmacy because of their social habits. The results were supported by the study conducted by Kumara Swamy RC et al (2014) ${ }^{[4]}$ where it is documented that out of the total 940 prescriptions, $479(50.95 \%)$ patients were male and $461(49.04 \%)$ patients were females.

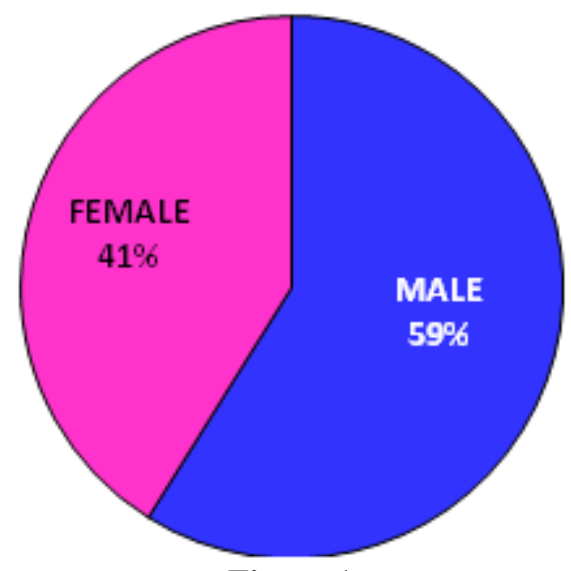

Figure 1

The patients were categorised according to their body mass index. 13(10.5\%) patients were found to be obese, 24 $(19.4 \%)$ were found to be overweight and $87(70.1 \%)$ were having normal body mass index.

Age categorisation (fig. 2 ) of patients revealed that the major fraction $68(54.8 \%$ ) of patients were of age group 60-69 years old, 42(33.8\%) were of age group 70-79, 9(7.2\%) were of age group $80-89$ while only $4 \%$ of the patients were above 90 years of age. The results were comparable with the study conducted by Akshaya B Srikanth et al (2012) ${ }^{[5]}$ were it is documented that major fraction $(64.07 \%)$ of the patients were in the age group of $19-45$ years old, while only $4.85 \%$ of the patients were above 70 years of age.

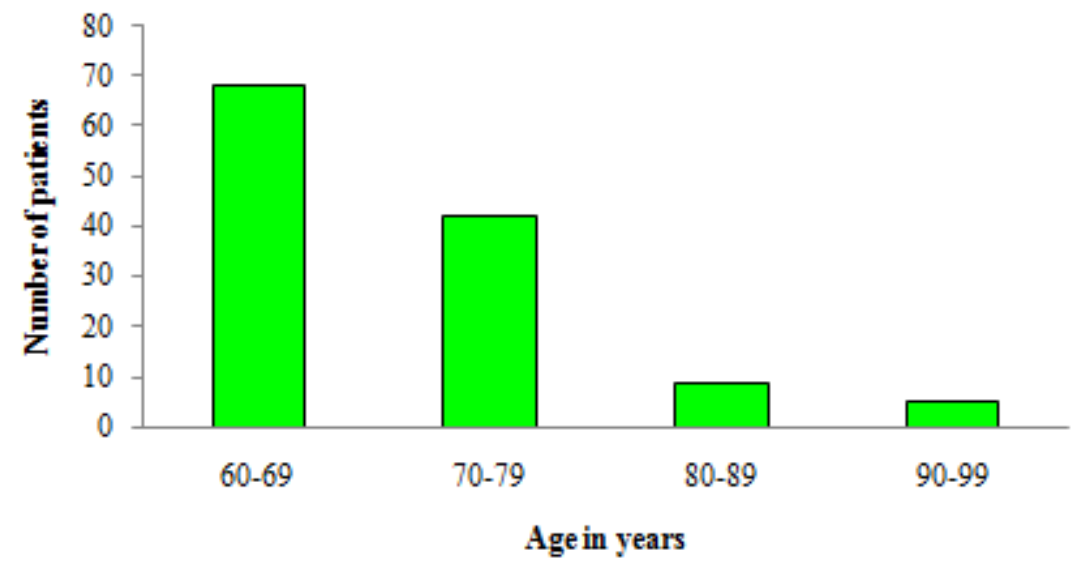

Figure 2

In this study the most common disorder found was hypertension with patients $43(34.6 \%)$, Type II diabetes mellitus with $39(31.4 \%)$, LRTI with $15(12.09 \%)$ and chronic renal failure with $14(11.2 \%)$. Other diagnosis observed were CVA, COPD, IHD, fever, gastritis, tuberculosis, UTI, hypothyroidism, HRAD, IWMI and CAD. The results were supported by the study conducted by Nimmy N John et al $(2014)^{[6]}$ in which it was studied that the most common disorders were hypertension with $27.3 \%$, type II diabetes mellitus with $22.4 \%$, chronic obstructive pulmonary disorder with $18.5 \%$ and ischemic heart disease with $15.4 \%$. Other diagnoses observed in our study population are congestive cardiac failure, urinary tract infection, rheumatoid arthritis, cirrhosis and hepatitis.

In the study population the major co-morbidities found were hypertension 52(41.9\%), diabetes mellitus 49(39.5\%) and CRF 11(7.74\%). Other co-morbidities include COPD, tuberculosis, ischemic heart disease, hypothyroidism, CVA, bronchial asthma, CCF, vertigo, trigeminal neuralgia, diabetic retinopathy, migraine, coronary artery disease, lung abscess, left ventricular dysfunction, parkinsonism, rheumatoid arthritis, HIV and interstitial lung disease. Similarly a study conducted by Mubarak N Al Ameri et al 


\section{International Journal of Science and Research (IJSR) \\ ISSN (Online): 2319-7064}

Index Copernicus Value (2013): 6.14 | Impact Factor (2014): 5.611

(2014) ${ }^{[7]}$ documented that more than half $(56 \%)$ of patients that were most commonly involved in poly-pharmacy, had co-morbidities of high blood pressure, diabetes and dyslipidaemia $23 \%, 18 \%$ and $15 \%$ respectively.

In our study, the patients were prescribed with 2 to 15 drugs at the time of discharge. The average number of drugs prescribed during discharge was found to be 7.6. It was found that $78.8 \%$ of population had been prescribed with 2-6 drugs, $16.03 \%$ with $7-10$ drugs and $5.17 \%$ with $11-15$ drugs. In our study, the number of drugs per prescription ranges from 6 drugs to the maximum of 20 drugs. On an average 12 drugs were prescribed per prescription .The mean of drugs given during treatment was found to be $10.35 \pm .2 .711$.It was found that $60.95 \%$ of population had been prescribed with 6 10 drugs, $37.09 \%$ with $11-15$ drugs and $5.64 \%$ with $16-20$ drugs. The results were supported by the study conducted by Nimmy N John et al (2013) ${ }^{[8]}$ documented that the population had been prescribed with minimum of 4 drugs to the maximum of 14 drugs. The average number of drugs been prescribed was found to be 9 . In their study $18 \%$ of population had been prescribed with $2-4$ drugs, $52.18 \%$ with more than 5 drugs and $27.52 \%$ with $9-12$ drugs. A very less percentage of the population $(1.18 \%)$ had been prescribed with more than 12 drugs.

In our study the majority of patients were prescribed with antibiotics $(70.16 \%)$ followed by proton pump inhibitors (54\%), anti-hypertensives(49.1\%), anti-emetics (45.1\%), anti-diabetics (42.7\%), anti-asthmatics (41.9) and $\mathrm{H}-2$ blockers (39.5\%). Similar study was conducted by Mahmoud Taleb et al (2014) $)^{[9]}$ and the results are comparable. The most common drug groups prescribed were ACE-inhibitors (39.3\%), followed by anti-platelets $(37.3 \%)$, lipid lowering drugs (statins) (31.9\%), beta-blockers (18.1), calcium channel blocker (19.2), nitrates (16.1) and diuretics (22.6).

The use of antimicrobials has been studied. The major class of antimicrobials prescribed were beta-lactam antibiotics $(64.23 \%)$ out of which $22(17.7 \%)$ were piperacillin + tazobactam, 17(13.37\%) with ceftriaxone, 14(11.2\%) with cefotaxime, $13(10.4 \%)$ with cefepime + tazobactum, $5(4.03 \%)$ with meropenem, $2(1.6 \%)$ with cefaperazone + sulbactum, cefuroxime and faropenem; and 1(0.80\%) with cefuroxime + clavulanic acid and amoxicillin + clavulanic acid. Other class of antimicrobials include fluoroquinolones (14.4\%), macrolides (4.8\%), aminoglycosides (4.8\%), tetracyclines $(0.8 \%)$, anti-tubercular drugs $(4.83 \%)$ and antifungals $(4.83 \%)$.

The Proton Pump Inhibitors usage in our study was pantoprazole 63(50.8\%), esomeprazole $3(2.41 \%)$ and rabeprazole $1(0.89 \%)$.

The use of insulin and oral anti-diabetic agents was studied .Insulin was given to the major population 38(30.6\%). Major oral hypoglycaemic drugs prescribed include metformin $7(5.6 \%)$; and combination with sulphonylureas like, glimepride + metformin and gliclazide + metformin $1(0.80 \%)$. sulphonylureas like glimepride $3(2.41 \%)$ and gliclazide $1(0.80 \%)$. Under the class thaizolidnediones, pioglitazone $1(0.80 \%)$ was prescribed and under alphaglucosidase inhibitor, voglibose $3(2.41 \%)$ was prescribed.

The use of anti-hypertensives was studied. Diuretic usage was $29(23.3 \%)$, beta-blockers $9(7.23 \%)$, calcium channel blocker 35(28.22\%), ACE Inhibitors 4(3.22\%), ARBs $10(8.06 \%)$ and alpha- blockers $7(5.64 \%)$.

Potentially inappropriate medication use was identified with the help of Beer's Criteria. The PIM use was observed in $60(48.3 \%)$ patients and patients without PIM use was 64(51.7\%).One, two, three and four PIMs were received by $31,17,8$ and 2 patients respectively(table 1,fig 3).This result is supported by a similar study conducted by Parthasarathi $G$ et $\mathrm{al}(2011)^{[10]}$ which documented that PIM use was observed both at admission and during hospital stay in $9(1.1 \%)$ patients \& One,two and three PIMs were received by 134 , 46 and 11 patients respectively.

As per the assessment done, aspirin 28(22.5\%) and clopidogrel 21(16.93) were highly prescribed inappropriate medication followed by alprazolam $8(6.45 \%)$, ipratropium bromide $7(5.64 \%)$, spironolactone $6(4.83 \%)$, ketorolac $4(3.22 \%)$, digoxin $3(2.4 \%)$, prazosin $3(2.4 \%)$, chloropheneramine maleate $3(2.4 \%)$, zolpidem $2(1.6 \%)$, lorazepam $2(1.6 \%)$, liquid paraffin $2(1.6 \%)$, carbamazepine $2(1.6 \%)$, hydroxyzine $1(0.80)$, amitryptyline $1(0.80)$ and amiodarone $1(0.80)$. In our study aspirin $28(22.5 \%)$ was the most commonly prescribed inappropriate drug in geriatric. The use of aspirin should be avoided as it may increase the risk of GI bleeding or peptic ulcer. The second most commonly prescribed inappropriate drug was clopidogrel $21(16.93 \%)$ along with aspirin which may increase the chances of stomach and intestinal bleeding. Alprazolam must be strictly avoided in geriatrics as it may increase the risk of cognitive impairment. Ipratropium bromide should be avoided in patients who have prostate enlargement and urinary tract problems as it may aggravate prostate problems and make urination difficult. Taking $>25 \mathrm{mg}$ of spironolactone per day in heart failure patients may increase the risk of hyperkalemia. Ketorolac and etodolac may increase the risk of GI bleeding. Digoxin at doses higher than $0.125 \mathrm{mg} /$ day decreases its renal clearance which may lead to increased risk of toxicity. Acetylcholinesterase inhibitors such as prazosin should be avoided as it has increased risk of orthostatic hypotension or bradycardia. Chlorpheneramine maleate, hydroxyzine and triprolidine have potent cholinergic effects so it should be avoided because of its side-effects such as drowsiness, blurred vision, dry mouth, difficulty in urination and constipation. Zolpidem should be avoided in geriatrics as it may cause serious side effects such as confusions, falls, and bone fractures. In general benzodiazepines like lorazepam and clonazepam should be avoided in geriatrics as it has increased risk of cognitive impairement, delirium, falls and fractures. Liquid paraffin when swallowed, it may accidently get inhaled and cause pneumonia. Carbamazepine use may aggravate SIADH (Syndrome of Inappropriate AntiDiuretic Hormone secretion) or hyponatremia. Teritary TCA, amitriptyline causes high anticholinergic effect resulting in orthostatic hypotension. Safety profile of low dose doxepin $(<6 \mathrm{mg} /$ day $)$ is recommended. Amiodarone is associated with multiple toxicities including thyroid disease, pulmonary 


\section{International Journal of Science and Research (IJSR) \\ ISSN (Online): 2319-7064 \\ Index Copernicus Value (2013): 6.14 | Impact Factor (2014): 5.611}

disorders and QT prolongation. IV dosing of insulin can cause higher risk of hypoglycemia.

Table 1: Potentially Inappropriate Medication in Different Age Group based on Beers Criteria

\begin{tabular}{|c|c|c|c|c|c|c|c|}
\hline $\begin{array}{c}\text { Age group(in } \\
\text { years) }\end{array}$ & $\begin{array}{c}\text { Number of } \\
\text { subjects }\end{array}$ & $\begin{array}{c}\text { Total number of } \\
\text { medications }\end{array}$ & $\begin{array}{c}\text { Total number of } \\
\text { IM }\end{array}$ & 1PIM & 2PIM & 3PIM & 4PIM \\
\hline $60-69$ & 68 & 692 & 51 & 16 & 8 & 5 & 1 \\
\hline $70-79$ & 42 & 461 & 44 & 12 & 8 & 4 & 1 \\
\hline $80-89$ & 9 & 75 & 3 & 1 & 1 & - & - \\
\hline$>90$ & 5 & 50 & 2 & 2 & - & - & - \\
\hline
\end{tabular}

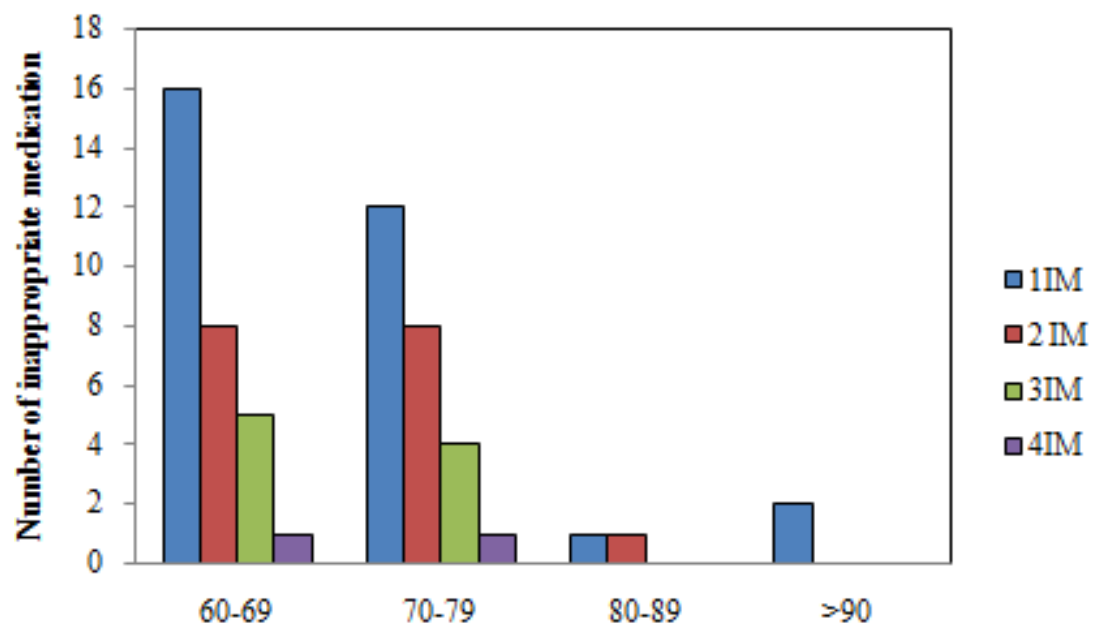

Age category(years)

Figure 3

The study population of 124 cases was thoroughly evaluated for drug interactions with the help of Micromedex software available with the Department of Pharmacy Practice. The results of the drug interaction study revealed that $112(90 \%)$ prescriptions had drug interactions and 12(10\%) prescriptions without drug interactions. From the 112 prescriptions we found that the average number of major interaction was $0.23 \pm 6.48$ and moderate interaction was $1.97 \pm 2.156$. Similar study by Akshaya B Srikanth et al (2012) ${ }^{[5]}$ revealed that out of 103 patients $11.65 \%$ prescriptions was with drug interactions.

Study on severity of the drug interactions revealed that there were 28 drug interactions with major severity in 18 prescriptions and 257 moderate interactions in 94 prescriptions. Similarly Nimmy N John et al (2013) ${ }^{[8]}$ observed that $20.1 \%$ were minor, $66.2 \%$ were moderate and $13.63 \%$ were severe interactions.

The study shows that males $73(58.9 \%)$ have used more drugs than females $51(41.1 \%)$. In this case there is no significant association between the number of drugs taken and the age group between male and female. Males were prescribed with more drugs than females, but the difference between the genders is not significant. Males of age 70-79 years were taking more number of drugs in relation to other age groups of the same gender $(\mathrm{p}=0.065)$.Average number of drugs used by males $(10.62 \pm 2.680)$ was higher than the average drugs used by females $(9.96 \pm 2.735)$. Males had more major interactions $(0.34 \pm 0.803)$ than females $(0.06 \pm$ $0.238)$. This shows significant difference between the gender $(\mathrm{p}=0.016)$.
The association between various variables were obtained using SPSS. On assessment of association between "number of drugs" with "number of PIMs", the result proved that "number of drugs" are statistically associated with the "number of PIMs" at 0.044 level of significance. This means that as the number of drugs increases, PIMs increases.

On assessment of association between "number of drugs" with "number of comorbidities", the result proved that "number of drugs" are statistically associated with "number of comorbidities" at 0.002 level of significance. This result proves that comorbidity is one of the reasons for polypharmacy.

Table 2: Association of Number of Drugs with Number of PIMs

\begin{tabular}{|c|c|c|c|c|c|c|}
\hline \multirow[b]{2}{*}{ S. No. } & \multirow{2}{*}{$\begin{array}{l}\text { Number of } \\
\text { PIMs }\end{array}$} & \multicolumn{3}{|c|}{ Number of drugs } & \multirow{2}{*}{$\begin{array}{l}\text { Chi- } \\
\text { square } \\
\text { value }\end{array}$} & \multirow{2}{*}{$\begin{array}{c}\mathrm{p}- \\
\text { value }\end{array}$} \\
\hline & & $\begin{array}{c}5-8 \\
\text { drugs }\end{array}$ & $\mid \begin{array}{c}9-11 \\
\text { drugs }\end{array}$ & $\begin{array}{l}>11 \\
\text { drugs }\end{array}$ & & \\
\hline 1. & Zero PIM & 22 & 28 & 14 & \multirow{3}{*}{9.268} & \multirow{3}{*}{0.044} \\
\hline 2. & One PIM & 10 & 12 & 10 & & \\
\hline 3. & $>$ One PIM & 3 & 11 & 14 & & \\
\hline
\end{tabular}

Table 3: Association of Number of Comorbidities and Number of Drugs

\begin{tabular}{|c|c|c|c|c|c|c|}
\hline \multirow[b]{2}{*}{ S No. } & \multirow[b]{2}{*}{$\begin{array}{l}\text { Number of } \\
\text { comorbidities }\end{array}$} & \multicolumn{3}{|c|}{ Number of drugs } & \multirow{2}{*}{$\begin{array}{l}\text { Chi- } \\
\text { square } \\
\text { test }\end{array}$} & \multirow[b]{2}{*}{$\begin{array}{c}\text { p- } \\
\text { value }\end{array}$} \\
\hline & & $\begin{array}{c}5-8 \\
\text { drugs }\end{array}$ & $\begin{array}{c}9-11 \\
\text { drugs }\end{array}$ & $\begin{array}{l}>11 \\
\text { drugs }\end{array}$ & & \\
\hline 11. & One & 12 & 9 & 3 & \multirow{3}{*}{17.204} & \multirow{3}{*}{0.002} \\
\hline 2. & Two & 14 & 29 & 13 & & \\
\hline 3. & $>$ Three & 9 & 13 & 22 & & \\
\hline
\end{tabular}




\section{International Journal of Science and Research (IJSR) \\ ISSN (Online): 2319-7064}

Index Copernicus Value (2013): 6.14 | Impact Factor (2014): 5.611

\section{Conclusion}

A prospective study was conducted in the general medicine department of a 750 bedded hospital.124 Geriatric patients were screened for prescription pattern studies.

Systemic hypertension $(34.6 \%)$ was the most common disorder followed by diabetes $(31.4 \%)$ and LRTI $(12.09 \%)$. The most common infections seen were respiratory tract infections $(12.09 \%)$ with concomitant diseases like diabetes mellitus $(41.9 \%)$ and systemic hypertension (39.5\%).60.95\% of the population had been prescribed with 6-10 drugs, $37.09 \%$ with $11-15$ drugs and $5.64 \%$ with 16-20 drugs during the hospital stay. $78.8 \%$ of population had been prescribed with 2-6 drugs, $16.03 \%$ with 7-10 drugs and $5.17 \%$ with $11-15$ drugs at discharge.

The results also revealed that antibacterials (70.16\%), vitamin supplements $(62 \%)$ and proton pump inhibitors (54\%) were the most commonly prescribed drug categories. The major classes of antimicrobials prescribed were betalactam antibiotics (64.23\%). Highly prescribed proton pump inhibitor was Pantoprazole (50.8\%). Among the diabetic patients Insulin was given to $30.6 \%$ of the population.Among the hypertensive patients, diuretics were prescribed the most common i.e., 23.3\%. Potentially inappropriate medication use was observed in $48.3 \%$ patients. Aspirin (22.5\%) and clopidogrel (16.93\%) was the most commonly prescribed potentially inappropriate medications. Drug interactions were assessed using Micromedex Software. $90 \%$ of study population was found to have prescriptions with drug interactions. 18 prescriptions had major drug interactions and 94 had moderate drug interactions. Drug category causing major drug interactions include mainly cardiovascular drugs $(33.33 \%)$. Statistical analysis using SPSS revealed that male population (58.9\%) received more drugs than female patients (41.1\%). The analysis also proved that there is close association between the number of drugs and the number of PIMs which was statistically significant at 0.044 level .Thus it revealed that, as the number of drugs increases, PIMs increases. Similarly statistical analysis showed that there was an association between the number of drugs and the number of comorbidities which was statistically significant at 0.02 This provides evidence that comorbidity is one of the reasons for polypharmacy.

This study demonstrated the need for professional attention and intervention by a clinical pharmacist to prevent and rectify problems due to polypharmacy in Geriatric population.Polypharmacy is most common among elderly patients. Various studies have shown that polypharmacy is related with negative health consequences and further research is required to describe the outcomes associated with avoidable drug use. Adherence to therapy, dosing \& careful administration can be a problem among elders therefore; vigilant efforts should be done in order to determine adverse drug events predominantly due to metabolic \& genetic susceptibility. Health care professionals must be aware of risks \& benefits related to each prescribed medication. All medications for each patient should be fully evaluated by the health care professionals in order to avoid polypharmacy.

\section{Future Scope}

The study may be extended to geriatric patients whose renal and hepatic functions are critical. Further the quality of life studies may be carried out in consultation with occupational therapist. Furthermore there are lot of scope to assess in future studies the consequences of inappropriate prescribing according to Beer's criteria, such as comparing the risk of falls and fractures in patient groups with or without inappropriate drug use. Comparing outcome could give us an idea to what extend these criteria are relevant in clinical practice and influence the prognosis of older patients.

\section{Funding}

No funding sources

\section{Conflict of interest}

None declared

\section{Acknowledgement}

The authors are grateful to all who have contributed to the success of this study. We specially acknowledge the Department of General Medicine of Sri Ramakrishna Hospital, Coimbatore, for the provision of the data. It is our privilege and wonderful experience to be part of this esteemed institution and we owe our sincere thanks to Thiru. R. Vijayakumhar Managing Trustee, SNR Sons Trust, Coimbatore.We are conceited to express our profound gratitude to Dr. P. Sukumaran, M.S., M.Ch., FIACS, Dean, SRH, Coimbatore who had permitted us and provided with the facilities to execute this work.We also thank Dr. T. K. Ravi, Principal, College of Pharmacy, SRIPMS, for his constant encouragement throughout the study.

\section{References}

[1] Eyigori S, Yesmin Gokce Kutsal. Polypharmacy in elderly to prescribe or not prescribeThat is the question. Turkish Journal of Geriatrics. 2012; 5(4):445-454.

[2] Couteur D, Sarah N Hilmer, Nicholas Glasgow, Vasi Naganathan, Robert G Cumming. Prescribing in older people. Australian Family Physician. 2004; 33(10): 777 781.

[3] Doubora S V, Hortensia Reyes Morales, Laura del Pilar Torres Arreola and Magdalena Suarez Ortega. Potential drug-drug interactions and drug-disease interactions in prescriptions for ambulatory patients over 50yrs of age in family medicine clinic. BMC Health Services Research.2007; 7: 1-8.

[4] Swamy K R C, Jignesh U Ramani, Bushipaka Ramesh, Mehul Radadiya, Sowmya B, Duruvil Patel.Prevalence Of Polypharmacy And Drug To Drug Interactions In A Tertiary Care Teaching Hospital. International Journal Of Pharmacy.2014;5(10):778-782.

[5] Akshaya B Srikanth, Sireesha G. Assesment On The Prevalence Of Polypharmacy In

[6] Urban Population. Invention Impact: Pharmacy Practice. 2012;(4):215-218. 


\section{International Journal of Science and Research (IJSR) \\ ISSN (Online): 2319-7064}

Index Copernicus Value (2013): 6.14 | Impact Factor (2014): 5.611

[7] John N N, Akshay N Kumar, A Study On Polypharmacy In Senior Indian Population.

[8] International Journal Of Pharmaceutical, Chemical And Biological Sciences. 2014;3(1):168- 171

[9] Al Ameri M N, Emad Makramalla, Umniya Albur, Anil Kumar, Padma Rao. Prevalenceof Poly-Pharmacy In The Elderly Implications Of Age, Gender, CoMorbidities And Drug Interactions. Soj Pharm Pharm Sci, 2014;1(3), 1-7.

[10] John N N, Udupi R H , Binu K M: Incidence Of Polypharmacy Induced Drug InteractionIn A Tertiary Care Hospital. Int J Pharm Sci Res, 2013; 3(7): 21192121.

[11] Taleb M, Abed Al-Kareem Abed, Abedel Rahman Dahudi, Ahmed Najim,Adham Ahmed Polypharmacy In Primary Care Practices Among Chronic Elderly Patients In Gaza Strip. Pharmacology \& Pharmacy, 2014; 5: 291-297.

[12] Parthasarathi G ,Harugeri A, Joseph J, Ramesh M, Guido S .A Study On Prevalence And Predictors Of Potentially Inappropriate Medication Use In Elderly Patients In Two Indian Teaching Hospitals. ICIUM 2011 